Clío América/ Vol. 12, No. 24 - 2018 / 202 - 218

DOI: http://dx:10.21676/23897848.3014

\title{
RIESGO Y PODER EN LAS ORGANIZACIONES GANADERAS EN COLOMBIA. ENFOQUE DESDE LA HISTORIOGRAFÍA ECONÓMICA, SOCIAL Y EMPRESARIAL
}

\author{
RISK AND POWER IN THE COLOMBIA CATTLE BREEDING ORGANIZATIONS: AN \\ ECONOMIC SOCIAL AND ENTREPRENEURIAL HISTORIOGRAPHICAL PERSPECTIVE
}

\section{Aylin Patricia Pertúz-Martínez ${ }^{1}$ (D) Jorge Enrique Elías-Caro ${ }^{\text {(D) }}$}

Tipología: Artículo de revisión

Para citar este artículo: Pertúz-Martínez, A. P. y Elías-Caro J. E. (2018). Riesgo y poder en las organizaciones ganaderas en Colombia enfoque desde la historiografía económica, social y empresarial. Clío América, 12(24), 202 - 218. doi: http://dx.doi.org/10.21676/23897848.3014

Recibido en julio 31 de 2018

Aceptado en 29 de octubre de 2018

Publicado en línea en 28 de noviembre de 2018

\section{RESUMEN}

Este trabajo tiene como objetivo identificar las organizaciones y actores sociales vinculados al sector ganadero colombiano en función del riesgo y las relaciones de poder, de acuerdo con lo registrado en la historiografía económica, social y empresarial. En lo metodológico, la investigación tiene un carácter cualitativo, un diseño documental y el método aplicado es deductivo - inductivo y analítico - sintético. Las fuentes consultadas son secundarias y corresponden a la historiografía que aborda los siglos XIX, XX y lo transcurrido del siglo XXI. Se concluye que las organizaciones ganaderas han sido conservadoras respecto al riesgo. La ganadería presenta riesgos del entorno y operativos. La historiografía clásica muestra a la ganadería como una actividad ec onómica que se encuentra muy ligada al poder y establece, de distintas formas y fuentes, la asociación entre la actividad ganadera y la política. Otros autores, desde lo económico y administrativo, analizan al ganadero como empresario más que como terrateniente, expresión muy ligada al poder.

Palabras clave: Colombia - organizaciones ganaderas - riesgo - poder - empresarios. JEL: M

\section{ABSTRACT}

This research has as a main aim to identify livestock organizations and social actors linked to the Colombian livestock sector based on risk and power relations using data sources from the economic, social and business historiography records. This research was done from a qualitative research perspective using a documentary design through a deductive - inductive and analytical - synthetic method. Secondary data sources corresponding to the XIX and XX century historiography was used. The findings show that livestock organizations have been conservative regarding risk. Livestock presents environmental and operational risks. It also shows that Classical historiography is closely linked to power and economic demonstrating different forms and sources such as the association of livestock-political activity. Other authors, from the economic and administrative point of view, have also analyzed the ranchers more as entrepreneurs than as landowners, a perspective more linked to highlight power in the region.

Keywords: Colombia - cattle breeding organizations - risk - power - entrepreneur.

1 Universidad de Sucre. Colombia. Email: aylin.pertuz@unisucre.edu.co ORCID: https://orcid.org/0000-0002-2414-336X

2 Universidad del Magdalena. Colombia. Email: joelcar1@ @otmail.com ORCID: https://orcid.org/0000-0003-0188-6133 


\section{INTRODUCCIÓN}

El trabajo explica desde un análisis historiográfico ciertas categorías conceptuales de las organizaciones $\mathrm{y}$ actores sociales vinculados al sector ganadero colombiano, en función del riesgo y las relaciones de poder que se establecen en el sector desde lo económico, social y empresarial.

Según Knight (1947), en el riesgo, la distribución de los sucesos en un grupo de casos es conocida, sea por un cálculo "a priori" o mediante estadísticas de experiencias anteriores; en cambio, en la incertidumbre no es posible formar un "grupo de casos" porque el evento que se presenta es único. Para Luhmann (2006) no existen conducta "libres de riesgo"; ello implica que no existe seguridad alguna.

Los riesgos son inevitables cuando se toman decisiones. No hay decisiones libres de riesgo, pero mientras más información e investigaciones se tengan, mayor será la conciencia del riesgo. En este sentido, la prevención influye en la disposición al riesgo y, de esta forma, también en una de las condiciones para que el daño pueda presentarse. En Beck (2002), el riesgo está ligado al proceso administrativo y de toma de decisiones.

En las organizaciones, señalan Bilbao y Rodríguez (2011), existen varios tipos de riesgo: operacional, de reputación, de crédito, de mercado, liquidez, legal y estratégico. También, según Mejía (2006), los riesgos empresariales pueden ser generados por el entorno (económico, social, político, legal, la región y el sector industrial) y por las operaciones de la empresa (generados por la naturaleza, reputación, especulativo, puro, estratégico, operativo, financiero, legal, tecnológico, laboral y físico). Por lo tanto, las organizaciones deben hacer uso de la gestión de riesgos para su direccionamiento y ejecución.

Hammond, Keeney y Raiffa (2008) exponen que la actitud ante el riesgo depende de cuán significativo considera una persona el resultado desfavorable, es decir, se determina la peor consecuencia de una decisión, al compararse con el resultado favorable. Para las personas que evitan correr riesgos, las consecuencias negativas pesan mucho más que las posibles ventajas.
En este estudio se describe al ganadero desde las perspectivas del poder, como el dominio ejercido, como algo propio, pero también desde las relaciones de poder en lo político y social; por esta razón, aunque las teorías puedan ser contrarias se hace uso de ellas como referentes teóricos.

Weber (1994) establece que el poder político tiene su base en tres tipos de dominación: la legal, con base en un estatuto; la tradicional, debida a la creencia en la "santidad de los ordenamientos" y los poderes de los señores que han existido siempre; y la carismática, desarrollada por la devoción afectiva a la persona del señor y a sus dotes excepcionales. Para Parsons (como se citó en Fernández, 2011), los medios del poder son elementos que sirven para controlar los medios de intercambio: el poder, el dinero y la influencia. Según Wright (1987) entre los medios de poder se encuentra: el poder de administrar y manipular el consentimiento de los individuos. Bourdieu (2000) enfatiza que el poder simbólico no se ejerce sino es "reconocido". Por su parte, Foucault (como se citó en Ávila, 2007) argumenta que el poder se mueve transversalmente, no permanece inmóvil en los individuos.

Luhmann (1995) establece que existe el poder organizacional y el poder personal, ya que ambos tienen como particularidad "el control sobre la contingencia, sobre sí y no en relación con los roles deseados". Según Peffer y Salancik (como se citó en Peffer, 1993) el poder es difícil de definir, pero no es difícil de reconocer: la habilidad de los que tienen el poder para obtener los resultados deseados. Mintzberg (1993) considera que existen tres bases del poder: el control de un recurso, de una habilidad técnica, y de un conjunto de conocimientos importantes para la organización. Morgan (1991) señala que el poder es el medio para resolver, en última instancia, los conflictos de intereses, y entre sus fuentes de poder se encuentra el poder compensador, aquel que no hace parte de la estructura de poder establecida.

\section{METODOLOGÍA}

La investigación fue cualitativa de tipo analíticodocumental y fuentes de información secundarias. La 
técnica utilizada para la obtención y sistematización de los datos fue la "interpretación hermenéutica", pues son el resultado, en primera medida, del balance bibliográfico que se realizó de la revisión de la literatura (diagnóstico y estado del arte), para, posteriormente, en la Tabla 1 desarrollar un análisis historiográfico longitudinal desde lo sucedido en el siglo XIX hasta lo que va corrido del siglo XXI. En la "metodología hermenéutica", la comprensión tuvo tres momentos: 1) comprensión; 2) interpretación o desarrollo de la compresión; 3) aplicación (Etchegaray, Chorroarin, Pac y Erramouspe, 2006).

Tabla 1. Inventario historiográfico.

\begin{tabular}{|lrr|lr|lr|lr|}
\hline \multicolumn{2}{|c|}{ Tipo de trabajo } & \multicolumn{2}{c|}{ Textos por periodo de edición } & \multicolumn{2}{c|}{ Siglo de estudio } & \multicolumn{2}{c|}{ Espacio } \\
\hline Libros & 26 & $1920 \mathrm{~s}$ & 1 & XIX: & 1 & Municipal: & 10 \\
\hline Artículos & 6 & $1930 \mathrm{~s}$ & 1 & XIX y XX: & 17 & Departamental: & 4 \\
\hline Trabajos de pregrado & 0 & $1960 \mathrm{~s}$ & 4 & XX: & 25 & Regional: & 25 \\
\hline Trabajos de posgrado & 2 & $1970 \mathrm{~s}$ & 2 & XX y 2000s & 16 & Nacional: & 20 \\
\hline Capítulo de libro: & 6 & $1980 \mathrm{~s}$ & 5 & & & & \\
\hline $\begin{array}{l}\text { Informes, ponencias y } \\
\text { documentos de trabajo: }\end{array}$ & 19 & $1990 \mathrm{~s}$ & 10 & & & \\
\hline & & $2000 \mathrm{~s}$ & 36 & & & \\
& & & & & & \\
\hline
\end{tabular}

Fuente: elaboración propia.

\section{RESULTADOS}

\section{El riesgo y el poder en las organizaciones ganaderas}

\section{La ganadería en Colombia:}

La ganadería vacuna llegó a Colombia desde la conquista española. En el siglo XX se implementaron diversos sistemas de producción; desde el sistema extractivo hasta el confinamiento, siendo este último, muy escaso, pero el sistema de producción más utilizado en el país es el pastoreo extensivo. La actividad, tanto cárnica como láctea, en su eslabón primario, presenta adelantos en el cruce de razas, uso de pastos artificiales, atención a los animales, pero su implementación no ha sido sistematizada ni generalizada. En el sector industrializado de la cadena láctea se cuenta con tecnología avanzada e innovación en los productos. Con base en los datos de la Federación Colombiana de Ganaderos (Fedegan), el inventario ganadero en Colombia hacia el año 2012 estaba cercano a los 24 millones de animales, y de acuerdo con Lerner, Zuluaga, Chará, Etter y Searchinger (2017), el $81 \%$ de las fincas ganaderas tienen menos de 50 cabezas de ganado.

\section{El riesgo en las organizaciones ganaderas}

Tipos de riesgo:

La ganadería asume riesgos internos y externos. La figura 1 muestra los riesgos externos, según Mejía (2006) y Bilbao y Rodríguez (2011) con base en la historiografía. 
Figura 1. Riesgos generados por el entorno. Finales siglo XIX - Principios del siglo XXI.

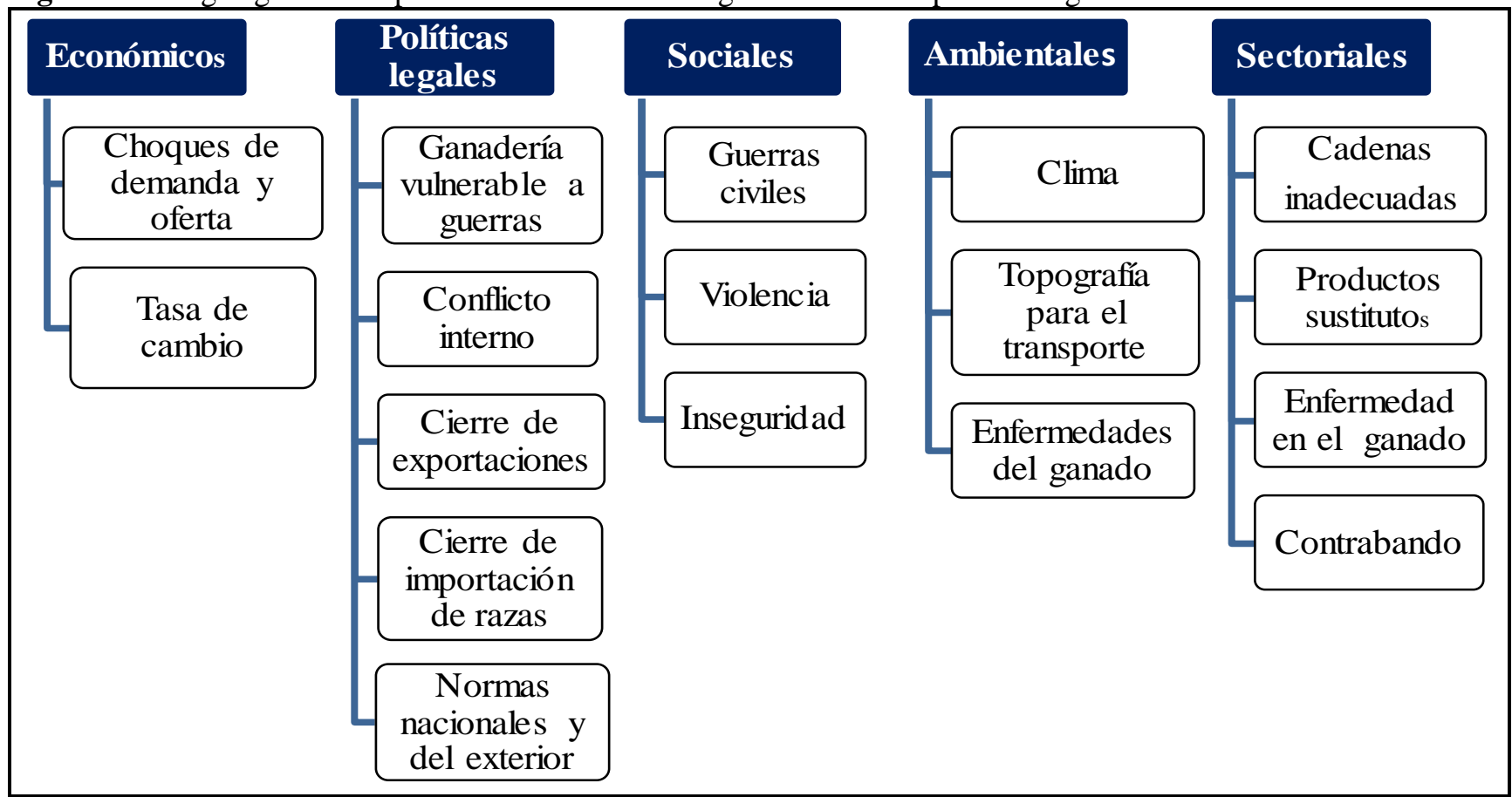

Fuente: elaboración propia basada en Jaramillo y Caicedo (1996), Arias (1998), Bolívar (2008), Pérez (2015), Cruz, Peñuela, Gómez y Cedeño (1972a), Brew (2000), Fedegan (2000), Posada (2006), Viloria (2003), Espinal, Martínez y Acevedo (2005), Cruz, Peñuela, Gómez y Cedeño (1972b).

Entre los riesgos generados por el entorno se encuentran los factores económicos. Los "choques" de oferta y demanda, los cuales, como establecen Rosen, Murphy y Scheinkman (como se citó en Jaramillo y Caicedo, 1996), tienen efectos sobre el inventario ganadero, así como efectos sobre los resultados en la producción en el corto plazo. En el ciclo ganadero, cuando los ganaderos ven un cambio positivo en el precio, en el siguiente período sacrifican menos hembras, con el fin de destinarlas a la reproducción, esperando mejores precios en el futuro.

Respecto al factor social, a finales del siglo XIX los ganaderos tuvieron que hacer frente a las guerras. Según Posada (1994) los ganaderos decidieron exportar ganado a Cuba y otras regiones, para escapar de esta situación. Algunos ganaderos que no exportaron quebraron, tal como señala Támara (1961) en el caso de Nicanor Vergara Gómez, quien perdió su inversión en la Guerra de los Mil Días.

En el siglo XX, según Arroyo (como se citó en Almario, 1994), en el sur del departamento del
Cauca, los ganaderos fueron ausentistas debido a la violencia política de los años cincuenta. Arias (1998) expresa que la inseguridad rural producto del conflicto generó una reubicación de la ganadería debido al incremento de la actividad guerrillera, manifestada en "boleteos", extorsiones y abigeato. En los años noventa también disminuyó la producción ganadera, en especial en zonas alejadas de los centros urbanos. Para Llorente (1994) la inseguridad frenó el progreso técnico de la ganadería. Las subastas hicieron su aparición. Pero, inclusive en las subastas, manifiesta Bonet (1998), al tratarse con personas desconocidas, se debía entregar un cheque de gerencia antes de retirar los animales. Según Viloria (2005) las subastas en el comienzo del siglo XXI fue una alternativa ante la inseguridad del campo.

Como riesgos legales, Posada (1994) señala que entre 1915 y 1919 se discutieron en el Congreso varios proyectos de ley en relación con el Packing House de Coveñas, lo cual retrasó su implementación, en parte, porque en el interior del país estaban en contra de la exportación. Respecto a 
las exportaciones, Bolívar (2008) expresa que, en 1913 se presentó un proyecto de ley que prohibía el sacrificio o exportación de reses por 20 años, y en época de conflictos se prohibía sacrificar reses hembras. Hacia 1974 la Comunidad Europea subsidió a sus productores por lo que se interrumpieron las exportaciones (Llorente, 1986). En cuanto a las importaciones, Pérez (2015) señala que la legislación cerró las importaciones de ganado cebú en 1931 y esta fue levantada en 1939.

Los riesgos ambientales han estado relacionados con; los ciclos climáticos (sequía-lluvias), la geografía, la presencia de regiones proclives al desarrollo de enfermedades en los animales y la fertilidad de las tierras en ciertas zonas para el cultivo de los pastos. Según Arrázola (1996) por la trocha de Manuel Torres, a principios de siglo XX, se hacía un viaje que de ida duraba dos a tres meses. Bonet (1998), expresa que para 1950, los animales de Bolívar llegaban por trochas y caminos a la Feria de Medellín, agotados, para ser vendidos como ganado flaco o de ceba. Los fenómenos asociados al clima, generaron la trashumancia de los bovinos, es así como según Botero (2010), en la región Momposina (Bolívar), es una actividad que aún continúa.

En los riesgos sectoriales se han presentado los problemas de encadenamiento, los productos sustitutos, las enfermedades del ganado y el contrabando. Para Posada (2006) las ganancias podían depender de la etapa de producción y del mercado (lo cual es también un riesgo operativo); así, el gran ganadero, que podía criar sus novillos y venderlos a los cuatro años, podía evitarse los intermediarios y estar en una mejor posición que los dedicados a la cría y levante.

De igual manera, cuando en el país se dio una disminución del consumo de carne bovina, según Cubillos (como se citó en Mendoza y Pérez, 2016), se debió al contrabando fronterizo, de menor calidad e inocuidad, pero con un precio más bajo. Aunque, Zapata (2006) expresa que, cuando el gobierno colombiano dictó medidas para evitar la salida de productos colombianos sin licencia de exportación, los ganaderos de Valledupar, hacia los años cincuenta, ejercían la actividad del contrabando.

Figura 2. Riesgos asociados a factores operativos en la actividad ganadera

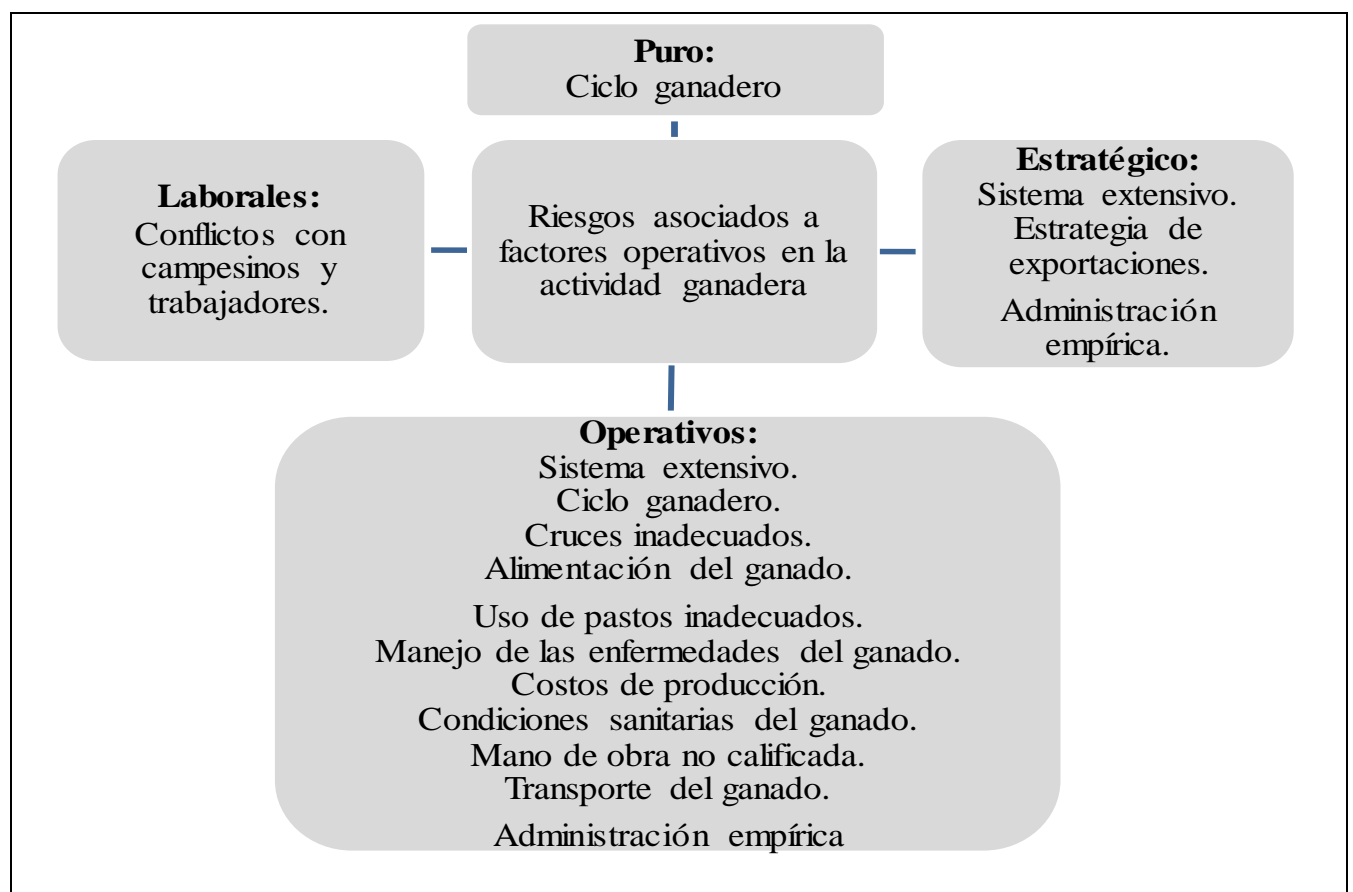

Fuente: elaboración propia basada en Vargas (1987), Fals (1976), Rivas y Holmann (2002), Meisel (2017), Cruz, Peñuela, Gómez y Cedeño (1972b), Staffe (1961), Llorente (1986), Posada (2006), Huertas (2006), Viloria (2003), Cruz, Peñuela, Gómez y Cedeño (1972b). 
Desde lo interno, los riesgos tipo puro están relacionados con el ciclo ganadero, tal como se observa en la figura 2. Según Llorente (1986) es un fenómeno afectado por las circunstancias que atraviese el país. Cuando el ganadero vende, aumentan sus ingresos, pero baja su capital productivo, y cuando no vende o retiene, disminuyen sus ingresos, pero acumula capital. En este sentido, el ganadero puede acumular cuando recibe créditos y tenderá a vender cuando paga los créditos, cuando bajan los precios o tiene necesidades de dinero.

En cuanto a los riesgos estratégicos, Posada (1988) señala que el pastoreo extensivo fue la alternativa económica más adecuada a las condiciones de la naturaleza del Caribe y su economía. También, en este tipo de riesgo, se encuentra la estrategia de exportaciones, que fueron intermitentes durante el siglo XX. Tal y como expresa Moré (2003) acerca del Packing House, su administración no tuvo un conocimiento claro y real de las potencialidades y riesgos del negocio en el campo internacional.

En los riesgos técnicos y organizacionales, como los laborales, a principios del siglo $\mathrm{XX}$, en el departamento de Bolívar, Fals (1976) explica que, la "matrícula" se impuso a sangre y fuego. Ocampo (2007) expone, acerca de la hacienda Marta Magdalena ubicada en el Sinú (Córdoba), que muchos de los conflictos entre empresarios y trabajadores fueron individuales, pero el conflicto extendido se presentó en varias épocas.

\section{Administración de Riesgos:}

Pepe Sierra (1848-1921), de acuerdo con Mejía (2011), buscaba mapas seguros para sus negocios y en la sociedad con Marciano Rozo, expresaba varias medidas de prevención en sus contratos, mostrándose minucioso para así evitar eventualidades.

En el caso de la familia Burgos, Hacienda Berástegui (Córdoba), durante el siglo XIX y principios del siglo XX, Negrette (2009) afirma que la diversificación de las inversiones disminuyó el riesgo empresarial.
Actitud frente al riesgo:

Támara (1961) expone que Nicanor Vergara (Corozal - Sucre) en el siglo XIX, llevaba una "excesiva economía", e imprimió en sus hijos el trabajo y el ahorro; empero, perdió su fortuna en la Guerra de los Mil Días. Según Mejía (2011), Pepe Sierra no llevaba el dinero a los bancos porque desconfiaba de ellos y era mejor invertirlo en tierras, entre otras opciones. Mientras Ocampo (2007) señala que en 1937 los miembros de la Sociedad Agrícola del Sinú anotaban que muchos cebadores bolivarenses tenían temor de hacer despachos al interior. Sin embargo, existieron ganaderos muy importantes que enviaron sus ganados a distintas regiones del país, como Antonio Guerra (Córdoba), Pedro Tulena (Córdoba), Adolfo Held (Bolívar), Antonio Lacharme (Córdoba), Arturo García (Sucre), Manuel de la Espriella (Santander), Valentión Parra (Santander).

Después de los años cincuenta, según Zapata (2006), el ganadero pensaba que, si bajaba el precio, simplemente ellos no ejercían ninguna actividad y el ganado seguiría allí; además, el ganadero no era amante de los lujos. Para el ganadero, en las primeras décadas del siglo XX, enviar sus ganados a otras regiones implicaba riesgos e incertidumbre, dado que los animales tenían que transitar por vastas zonas caminando, por ello, los ganaderos instalaron paradas para el descanso de los animales, además de poder curarlos y engordarlos.

\section{El poder en las organizaciones ganaderas}

Poder y relaciones políticas:

En el siglo XIX, fuentes de poder para el ganadero lo constituyeron, principalmente, la acumulación de capital y la apropiación de tierras baldías en el origen de la gran hacienda, (que continuó en parte del siglo $\mathrm{XX}$ ), de los ejidos, de las tierras comunales y los resguardos, como se observa en la figura 3. Claro está que, de acuerdo con Solano, Flórez y Malkun (2010), los ganaderos deseaban las tierras ya civilizadas, 0 que estaban próximos de centros urbanos o de acopio para exportación, además, a muchas tierras les dieron el título de baldíos. 
Figura 3. Poder en los ganaderos. Siglos XIX y XXI.

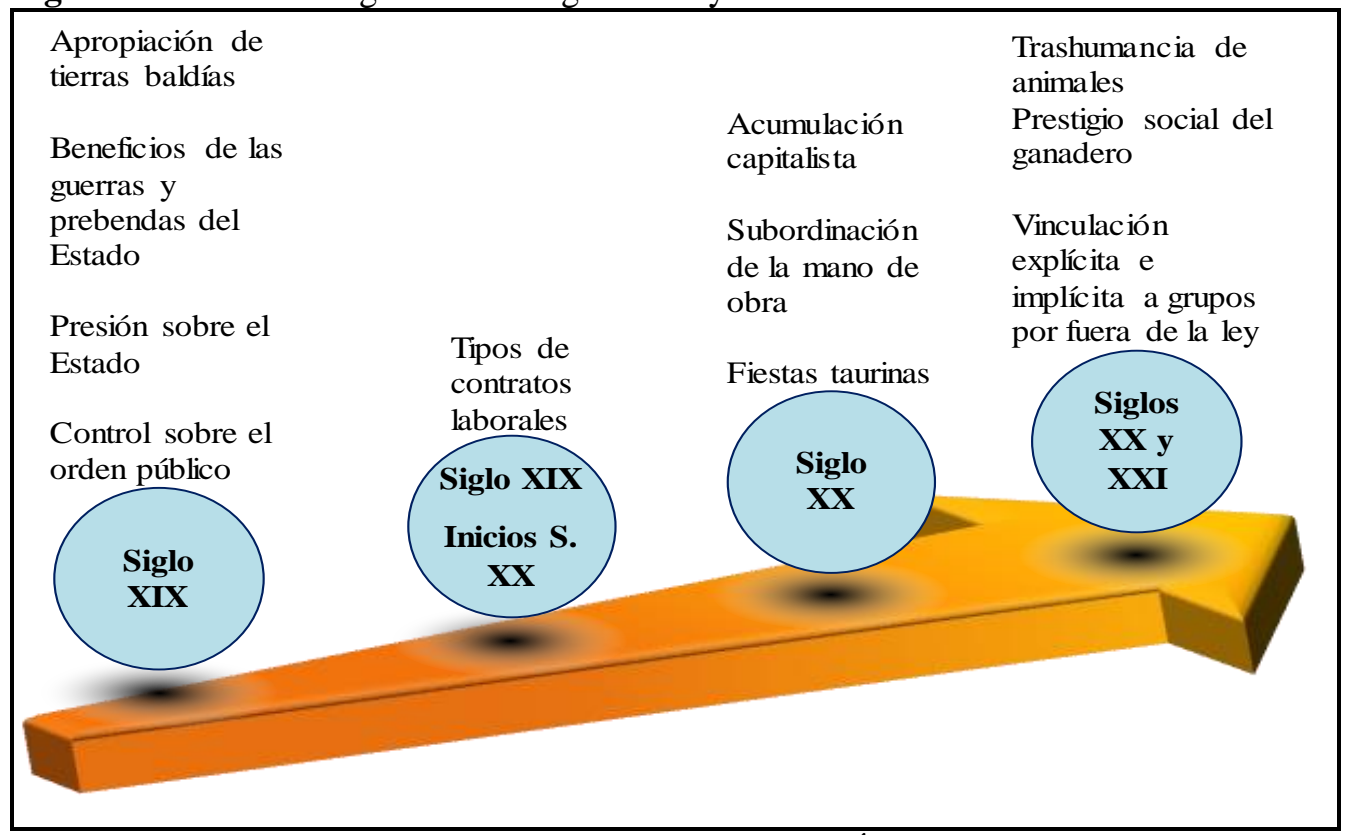

Fuente: elaboración propia basada en Solano (2008), Álvarez (2015), Flórez (2010), Posada (2006), Huertas (2006), Arias (2004), Romero (como se citó en Flórez, 2008), Arias (1998).

Legrand (1988) anota que en algunas ocasiones los campesinos se quedaron con la tierra, en otros casos, los terratenientes compraron las mejoras hechas por colonos, pero en general, fueron los campesinos los que perdieron en esta lucha de poder. La conformación de tierras por desposesión de los campesinos se dio en gran proporción entre los años 1870 a 1920. En la segunda mitad del siglo XIX, los terratenientes subordinaron la mano de obra mediante formas contractuales, o mediante la obligación para el campesino de comprar en las tiendas ubicadas en las haciendas. Reyes (1978) muestra como para los hacendados fue más económico dejar a los campesinos con una posesión precaria y temporal de pequeños lotes de bosque, donde pudiesen obtener su subsistencia, y así produjeran pastos artificiales para la hacienda.

Fals (1986) también establece como mecanismo de dominación los "avances" (anticipos de dinero). Para Posada (1988), el avance era exigencia de los trabajadores al hacendado. Ocampo (2007), muestra el avance como un ejercicio de poder sobre los jornaleros, pero también muestra el interés de los administradores de Marta Magdalena por acabar con esta práctica y el deseo de los trabajadores para que se mantuviera.

De igual forma, se presentaron: el no pago de impuestos por parte de los ganaderos, puesto que presionaban de manera conjunta al Estado para la supresión de impuestos en ciertas partes de la cadena en la actividad primaria; el control sobre el orden público, al proteger comunidades desprotegidas por el Estado; la obtención de beneficios del Estado, gracias a las guerras. Para Solano et al. (2010), las guerras no necesariamente eran perjudiciales para los grandes ganaderos.

Otra fuente de poder, en los siglos XIX y XX, 10 constituyó la posesión del ganado y la trashumancia. Con la trashumancia, los propietarios de terrenos que se encontraban a orillas de los caminos no podían hacer nada para detener el paso del ganado que iba alimentándose de las pajas y rastrojos. Como expresa Aguilera (2004), a principios del siglo XXI, la región de la Mojana era utilizada por los ganaderos de Córdoba, Bolívar y Sucre para llevar allí su ganado, ocasionando conflictos entre los propietarios y las personas sin tierra. Los ganaderos han sedimentado artificialmente los "playones comunales" como método para expandir los límites de sus propiedades. 
De lo social y cultural también han obtenido poder los ganaderos: las fiestas taurinas ligadas al poder económico y político. La corraleja fue el espacio en donde el ganadero imprimió todo su poder al convertirse en su promotor; siendo también un espacio donde se recreaba la estratificación social de la región, según indica Romero (como se citó en Flórez, 2008). Para la segunda década del siglo XX, expresan Solano y Flórez (2007), las corralejas eran parte de las fiestas patronales y el hacendado era el personaje central de la vida económica, social y política del Bolívar grande.

Los campesinos también mostraron su poder. Romero (como se citó en Flórez, 2008) expresa que, en Montería, en 1971, los campesinos excluidos de la reforma agraria y educativa se vengaron de los ganaderos en plena corraleja. Las corralejas y el prestigio personal del ganadero iban de la mano.
Los empresarios, para Legrand (1988), deseaban producir dinero y posición social. Reyes (como se citó en Ocampo, 2014) explica que los hacendados brindaban empleo, remuneración, en ocasiones tierra y vivienda, consejo, ayuda en momentos difíciles e intermediación. Los trabajadores entregaban su trabajo, apoyo y "servicios extra laborales". De acuerdo con Fals (1986) existía un equilibrio entre hacendados y pueblo, pero posteriormente esto se perdió cuando el ganadero pagaba todo con su dinero.

Acerca de la vinculación de los ganaderos a grupos al margen de la ley en los últimos años del siglo XX, Arias (1998) expresa que, la vinculación de organizaciones ganaderas a grupos paramilitares de forma explícita o implícita, los asoció al paramilitarismo y a la derecha.

Figura 4. Poder y asociación política. Siglos XIX y XX.

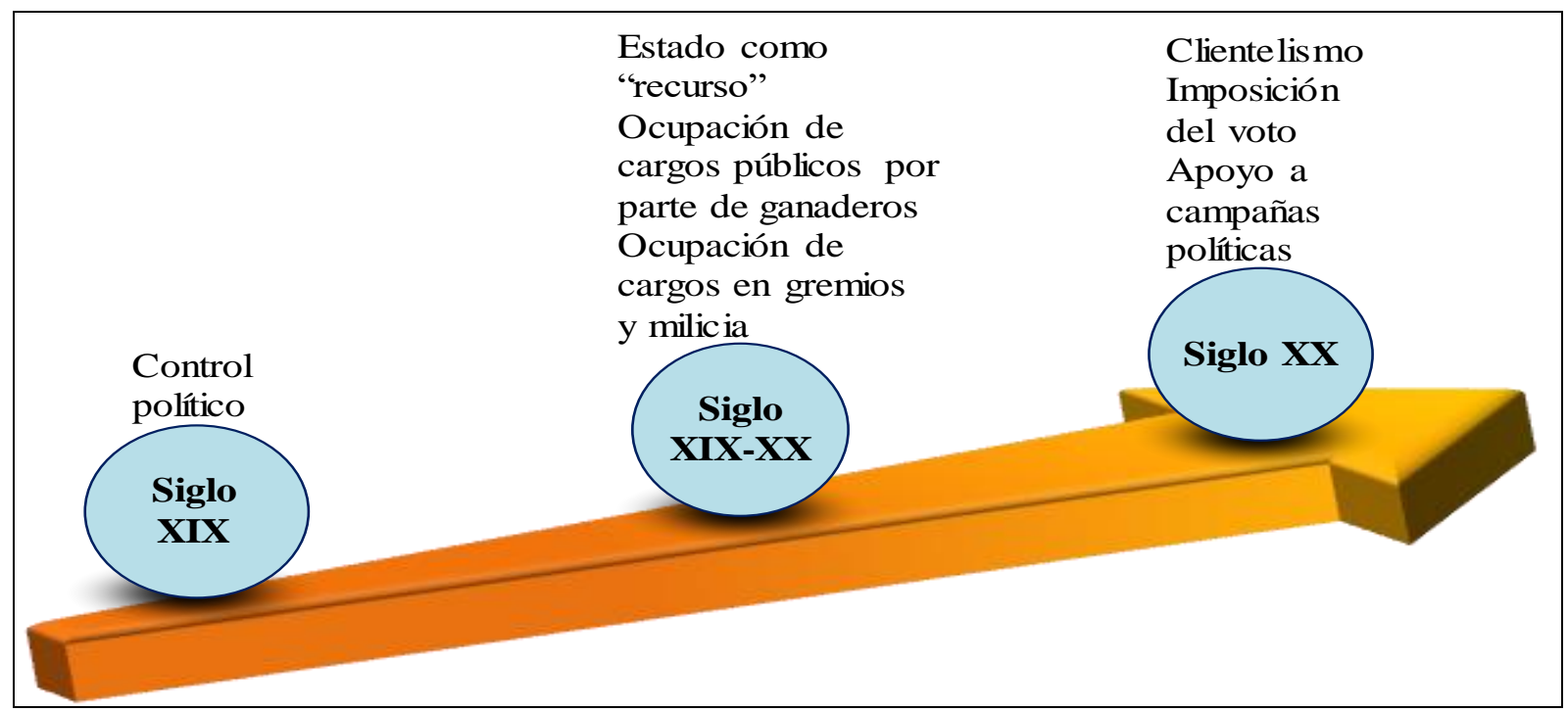

Fuente: elaboración propia basada en Flórez (2008), Pertuz (2008), Burgos (2000), Ripoll (1999), Bossa (1967), López (1927), Díaz (1935).

La asociación entre ganadería y política, según Díaz (1935) se expresa en figuras como la de Rogelio Támara, que dirigió las riendas de su partido, razón por la cual le llamaban "el jefe". Igualmente, manifiesta que, Arturo García era considerado el hombre más poderoso en la región sucreña y su esposa Concepción entregaba dinero a las campañas del partido liberal. Por otra parte, el fenómeno del clientelismo, como se muestra en la figura 4 , se fue presentando, según Reyes (1978), como una forma de control político sobre las bases electorales.

La participación de los ganaderos en organismos de decisión e influencia se observa en la actuación de Leopoldo Támara, quien fue vicepresidente de la 
Cámara de Comercio de Sincelejo en 1941 (Pertuz, 2008), o en Carlos Vélez Daníes quien fue Comandante en la Guerra de los Mil Días (Ripoll, 1997). Cunninghame (1968) señala que, hacia 1918, los miembros de la familia Burgos habían tomado parte en varias revoluciones civiles.

Organización ganadera y formas de poder:

En el ámbito sectorial, Gallini (2008) señala que hacia los años treinta del siglo XX, los ganaderos controvertían la necesidad, o no, del ganado cebú, haciendo visibles las diferencias que en ocasiones se presentaban entre ellos. Sin embargo, los ganaderos, de forma conjunta, realizaron presión ante el Estado por los intentos de reforma agraria que algunos gobiernos presentaron al país. Mientras, según Bagley y Botero (1994), las diferencias en la Asociación Nacional de Usuarios Campesinos de Colombia, en los años setenta, no permitieron la consolidación del campesinado.

De acuerdo con Vargas (1987), la estructura oligopólica de la industria láctea ha sido la razón del nulo poder de negociación de los productores, pues existe un gran dominio de los industriales sobre los pequeños productores de leche, quienes carecen de opciones para negociar los precios al encontrarse atomizados (Jaramillo y Areiza, 2013). En la cadena cárnica, específicamente, en la comercialización del ganado, el poder de negociación puede observarse en la Feria Ganadera de Medellín en donde, según Londoño (2013), los compradores de ganado gordo tienen poder de negociación sobre las empresas ganaderas, debido a que ellos son pocos y sus volúmenes de compra son grandes. Los pequeños comerciantes se unen para hacer una sola compra

A nivel organizacional, Ocampo (2007) revela que en la Hacienda Marta Magdalena, en las primeras décadas del siglo XX, los trabajadores que violaban principios y órdenes eran castigados. De igual manera, Botero (2010) afirma que, actualmente, en la región de la depresión momposina, se han conservado rasgos hacendatarios; porque para las ganaderías los trabajadores aún se conciben como de "Fulano o Zutano", perpetuando una percepción de propiedad que facilita la trashumancia.

\section{DISCUSIÓN}

En los riesgos de carácter económico, las decisiones tomadas por los empresarios, fruto del ciclo ganadero, son consecuentes con lo expresado por Knight (1947), es decir, lo que se arriesga en relación con las ganancias a recibir.

Las diferentes guerras que sufrió el país en el siglo XIX y el conflicto interno en parte del siglo XX y lo transcurrido del XXI, han generado un alto riesgo e incertidumbre para el desarrollo de la actividad ganadera, al estar asentada en el campo. Para hacer frente a los conflictos bélicos en el siglo XIX, Posada (1994) considera que la exportación de productos del sector ganadero hacia Cuba se realizó con el fin de poder escapar a dicha situación, en cambio para Meisel (2017), este hecho es solo una oportunidad de negocios por la demanda de ganados en países del Caribe. Estos factores de conflicto han moldeado la conducta del ganadero, en cuanto a sus decisiones, es decir, desplazamiento, falta de inversión, abandono de la actividad de forma temporal o permanente, estancamiento o disminución del inventario.

Los riesgos legales son puestos en marcha por intereses económicos sectoriales o conocimiento sesgado del negocio. Estas normas, en diversos periodos, no han permitido a los ganaderos aprovechar oportunidades internacionales, expandir razas de ganado o desarrollar innovaciones. En los riesgos ambientales, la geografía colombiana hacia el interior del país, no ha sido propicia para el desarrollo de medios de transporte como en otros países dificultando la actividad.

Los riesgos sectoriales relacionados con el encadenamiento productivo están presentes en la cadena cárnica y la cadena láctea, sin embargo, la cadena láctea ha mejorado de forma importante. Para el sector, el consumo de pollo es una amenaza, al tener un precio más bajo y un amplio crecimiento en las últimas décadas.

En los riesgos operativos, el pastoreo extensivo es 
una estrategia para minimizar el riesgo, sin embargo, estrategias como la exportación que para algunas empresas terminaron en fracasos, sustentan lo establecido por Beck (2002): el riesgo ligado a la toma de decisiones. Los riesgos operativos son persistentes en la ganadería colombiana, es así como, en la historiografía, respecto a los riesgos laborales, se muestra una estela de conflictos entre los ganaderos y los trabajadores o campesinos.

En cuanto a la administración de riesgos, no puede hablarse técnicamente de la existencia de métodos en estas empresas, aunque pueden observarse acciones no sistematizadas. Para Luhmann (2006) la prevención influye en la disposición del riesgo. Los autores Negrette (2009) y Posada (1988) divergen en la estrategia de diversificación de inversiones de la familia Burgos, como la puesta en marcha de una plantación de azúcar, pues mientras para Negrette disminuye el riesgo, para Posada, es una desventaja. Después de los años cincuenta del siglo XX, los ganaderos consideran que su actividad es menos riesgosa que la agricultura. En su actitud ante el riesgo, el ganadero es prudente.

En la historiografía, desde los clásicos, como Fals (1976) o Reyes (1978), el ganadero es visto como latifundista, terrateniente, cacique o gamonal, pero, los autores más recientes, como Viloria (2005) o Posada (1994), lo denominan empresario, reconociendo su actividad económica y empresarial.

En el siglo XIX y principios del XX, la acumulación de capital se expresa, para los autores clásicos, en relaciones injustas para el campesino en el latifundio. Se aprecia el poder como dominación, tendiendo a una dominación tradicional, según Weber (1994). En cuanto al "avance" dado a los campesinos, a diferencia de Fals (1976), para Posada (1988), este era exigencia de los campesinos o trabajadores al hacendado. En Ocampo (2007), en este sistema de relaciones de poder se expone lo expresado por Foucault, para quien, el poder circula hasta cierto punto.

En las fuentes de poder social y cultural, se observa una forma de administrar y manipular el consentimiento de una población, según lo establecido por Wright (1987), y de igual forma, se expresa el reconocimiento de un personaje de la élite por parte de la sociedad, según Bourdieu (2000).

La relación, ganadero con prestigio y pagos de dinero a los pobladores en las corralejas, es concordante con lo establecido por Parsons (como se citó en Fernández, 2011). El control del recurso dinero, es una evidencia de lo manifestado por Mintzberg (1993). La literatura de gran parte del siglo XX considera que el objetivo del terrateniente es la tenencia de la tierra, sin embargo, para autores más recientes el ganadero aspira a rentabilidad y estatus.

La participación en política ha sido una fuente de poder muy relevante para los ganaderos. Además de ser el Estado un "recurso" que se aprovecha para los intereses particulares y sectoriales, tanto en el siglo XIX como en el siglo XX, inclusive en lo trascurrido del XXI, la presencia de ganaderos en cargos públicos o dirección de partidos no es un hecho esporádico o casual. Un aspecto común es la financiación de campañas políticas. La participación de los ganaderos en organismos de decisión e influencia, se presenta en juntas directivas de Cámaras de Comercio y en cargos militares. Poder personal, en este caso, según Luhmann (1995), relacionado con el empleo que se ocupa o desea

También se observan dos formas de poder por parte de las organizaciones ganaderas y sus propietarios: en primer lugar, la posición de dominio que se desprende de la acumulación de capital, el Estado como recurso, la subordinación de la mano de obra, entre otras fuentes. Y en segundo lugar, la presión sobre grupos de referencia, en donde los ganaderos realizan gestiones para presionar a competidores, gremios, asociaciones, o el Estado. Pero no siempre hay unanimidad de intereses entre los ganaderos. Se observan en este caso distintos tipos de influyentes, que tienen sus propias necesidades y quieren satisfacerlas, según lo planteado por Mintzberg (1993). Ahora bien, no siempre han tenido éxito en la presión a un grupo de referencia

Acerca del poder compensador, señalado por Morgan (1991), en algunos momentos del siglo XX, los campesinos generan esta fuente de poder, que termina en violencia en algunos casos. Al final del siglo XX, la mano de obra campesina termina con un 
poder compensador fragmentado, beneficiando el poder de los ganaderos. En las cadenas láctea y cárnica es visible el poder de negociación de la industria sobre la fase primaria.

A nivel organizacional, en muchos casos, la administración tradicional genera procesos de control flexibles, pero no por la entrega de autonomía al trabajador, sino por la falta de implementación de técnicas de control. Algunas haciendas ejercen un control estricto, en donde esta función, además de ser una función administrativa, es una expresión del poder del ganadero sobre los campesinos o trabajadores. El paternalismo de muchos ganaderos propicia un control hacia la persona del trabajador como tal. El poder también es un mecanismo para dirimir los conflictos entre superiores y subordinados y entre subordinados. El poder en las organizaciones ganaderas está expresado en la capacidad de otorgar recompensas y castigo.

\section{CONCLUSIÓN}

Los ganaderos han sido conservadores respecto al riesgo en la toma de decisiones. Para muchos, incursionar en la ganadería, fue producto de la incertidumbre del sector agrícola. Igualmente, la ganadería extensiva, es una muestra de este conservadurismo, permeado por condiciones del contexto económico, social y competitivo.

Los riesgos operativos pueden ser más del control de los ganaderos, a diferencia de los riesgos del entorno, que por su naturaleza no son controlables por el empresario -aunque en algunos casos, los empresarios en conjunto pueden ejercer presión-. El pastoreo extensivo utilizado en el país, hace que los riesgos operativos tomen dimensiones de gran complejidad.

Las denominaciones al ganadero son diferentes entre los autores clásicos y los más recientes, viéndose el poder como dominación de un ganadero sobre los campesinos, o como un sistema de relaciones, es decir, un proceso en movimiento entre los distintos actores.

La relación ganadería y política se expresa en la utilización del Estado como recurso, el clientelismo, la imposición del voto y el control político o la ocupación por parte de ganaderos en cargos públicos. En los siglos XIX y XX, la conjunción con el Estado les permitió a muchos ganaderos obtener mayores y mejores tierras. La mano de obra campesina, ha luchado contra las distintas formas de poder, pero no ha podido hacer frente a una estructura consolidada. Estructura que direcciona $o$ reproduce un pensamiento del poder como dominación, propio de un sistema capitalista y del modelo de desarrollo implementado.

Sectorialmente puede observarse, el poder de la industria en la cadena láctea sobre los productores. Al nivel organizacional, en el siglo XX, algunas haciendas muy reconocidas generaron procesos de control en búsqueda de eficiencia, pero la gran mayoría, ha tenido una administración tradicional.

\section{Declaración sobre conflicto de interés}

Manifestamos nuestra independencia de las instituciones financiadoras y de apoyo. Durante la ejecución del trabajo o la redacción del manuscrito no han incidido intereses o valores distintos a los que usualmente tiene la investigación.

\section{REFERENCIAS BIBLIOGRÁFICAS}

Aguilera, M. (2004). La Mojana, riqueza natural y potencial económico (48). Recuperado de http://www.banrep.gov.co/es/contenido s/publicacion/mojana-riqueza-naturaly-potencial-econ-mico

Almario, O. (1994). La configuración moderna del Valle del Cauca, Colombia, 1850 1940. Cali, Colombia: CECAN Editores.

Álvarez, J. (2015). Legislación sobre tierras e 
RIESGO Y PODER EN LAS ORGANIZACIONES GANADERAS EN COLOMBIA. ENFOQUE DESDE LA HISTORIOGRAFÍA ECONÓMICA, SOCIAL Y EMPRESARIAL

impacto en el desarrollo de haciendas ganaderas en el Magdalena Medio antioqueño, 1920 - 1940. Historia y Sociedad, (29), 203-228. Recuperado de http://revistas.unal.edu.co/index.php/his ysoc/article/view/50595/51479

Arias, J. (1998). La ganadería en la formación social colombiana. Bogotá, Colombia: Ministerio de Agricultura.

Arias, J. (2004). Ganadería, paisaje, territorio y región. Una Historia Ecológica y Social de la Orinoquia Colombiana. Bogotá, Colombia: Documento inédito.

Arrázola, A. (1996). El veinte de enero. Historias de Sincelejo. Bogotá, Colombia: Plaza \& Janes.

Ávila, F. (2007). El concepto de poder en Michel Foucault. Telos, 8(2), 215-234. Recuperado de http://www.redalyc.org/articulo.oa?id= 99318557005

Bagley, B. y Botero, F. (1994). Organizaciones campesinas contemporáneas en Colombia: un estudio de la Asociación Nacional de Usuarios Campesinos. En A. Machado (Ed.), El Agro y la cuestión social (185-228). Bogotá, Colombia: Tercer Mundo.

Beck, U. (2002). La sociedad del riesgo global.
Madrid, España: Siglo XXI Editores.

Bilbao, P. y Rodríguez, J. (2011). La gestión del riesgo y el gobierno corporativo (Boletín de Estudios Económicos No. (66) 202). Recuperado de http://search.proquest.com/business/do cview/1314736318/fulltextPDF/A39B0 6F25F2944CFPQ/1?accountid=49118

Bolívar, I. (2008). Discursos estatales y geografía de consumo de carne de res en Colombia. En A. Flórez (Ed.), El poder de la carne (230- 289). Bogotá, Colombia: Universidad Pontificia Bolivariana.

Bonet, J. (1998). El Ganado Costeño en la Feria de Medellín, 1950-1997 (5). Recuperado de

http://www.banrep.gov.co/es/contenidos /publicacion/ganado-coste-o-feriamedell-n-1950-1997

Bossa, D. (1967). Cartagena independiente tradición y desarrollo. Bogotá, Colombia: Tercer Mundo.

Botero, L. (2010). Trashumancia y dinámicas culturales. Sabanas de Magangué y planicie inundable de Santa Cruz de Mompox, región Caribe colombiana (tesis de posgrado). Pontificia Universidad Javeriana, Bogotá, Colombia. 
Bourdieu, P. (2000). Sobre el poder simbólico., En A. Gutiérrez. (Traducción), Intelectuales, política y poder (65-73).

Buenos Aires, Argentina: UBA/ Eudeba. Recuperado de https://sociologiac.net/biblio/Bourdieu_So brePoderSimbolico.pdf

Brew, R. (2000). El desarrollo económico de Antioquia desde la independencia hasta 1920. Medellín, Colombia: Universidad de Antioquia.

Burgos, R. (2000). El general Burgos. Segunda edición. Cartagena, Colombia: Gobernación de Bolívar.

Cruz, J., Peñuela, J., Gómez, F. y Cedeño, G. (1972a). Bases para el desarrollo de la ganadería bovina en Colombia Tomo II. Bogotá, Colombia: Instituto Colombiano Agropecuario.

Cruz, J., Peñuela, J., Gómez, F. y Cedeño, G. (1972b). Bases para el desarrollo de la ganadería bovina en Colombia Tomo I. Bogotá, Colombia: Instituto Colombiano Agropecuario.

Cunninghame, R. (1968). Cartagena y las riberas del Sinú. Montería, Colombia: Departamento de Córdoba.

Díaz, A. (1935). Sinú. Pasión y vida del trópico. Bogotá, Colombia: Santafé.
Espinal, F., Martínez, H. y Acevedo, J. (2005). La cadena de carne bovina en Colombia. Una mirada global de su estructura y dinámica 1991 - 2005 (73). Recuperado de $\underline{\text { http://bibliotecadigital.agronet.gov.co/b }}$ itstream/11348/6320/2/2005112144930 _caracterizacion_bovina.pdf

Etchegaray, R., Chorroarin, S., Pac, A. y Erramouspe, P. (2006). La contribución hermenéutica a la teoría social y a los estudios culturales. Recuperado de repositoriocyt.unlam.edu.ar/biblioteca/ A107.pdf

Fals, O. (1976). Capitalismo hacienda y poblamiento en la costa Atlántica. Bogotá, Colombia: Punta de Lanza.

Fals, O. (1986). Retorno a la tierra. Historia doble de la costa. Tomo IV. Bogotá, Colombia: Carlos Valencia Editores.

Federación Colombiana de Ganaderos Fedegan. (2000). La ganadería bovina en Colombia.1999 - 2000. Bogotá, Colombia: Federación Colombiana de Ganaderos.

Fernández, S. (2011). Teoría, sociedad y poder en Talcott Parsons, C. Wright Mills, Jurgen Habermas y Anthony Giddens (tesis de posgrado). Recuperado de http://bibliotecadigital.uca.edu.ar/repo 
RIESGO Y PODER EN LAS ORGANIZACIONES GANADERAS EN COLOMBIA. ENFOQUE DESDE LA HISTORIOGRAFÍA ECONÓMICA, SOCIAL Y EMPRESARIAL

$\underline{\text { sitorio/tesis/teoria-sociedad-poder- }}$

talcott.pdf

Flórez, A. (2008). Ganado ¿para qué? En A. Flórez (Ed.), El poder de la carne. (pp. 118-163). Bogotá, Colombia: Universidad Pontificia Bolivariana.

Flórez, R. (2010). Orden público y seguridad: la protección privada de los ciudadanos en el Estado Soberano de Bolívar, 1857 1886. HiSTOReLO, 2(4), 44 - 72. Recuperado de https://revistas.unal.edu.co/index.php/his torelo/article/view/12263/pdf 24

Gallini, S. (2008). De razas y carne. En A. Flórez (Ed.), El poder de la carne (pp.290 337). Bogotá, Colombia: Universidad Pontificia Bolivariana.

Hammond, J., Kenney, R. y Raiffa, H. (2008). Decisiones inteligentes. Bogotá, Colombia: Norma.

Huertas, H. (2006). San Marcos del Carate: Historia Social de un Pueblo Anfibio. Medellín, Colombia: Lealon.

Jaramillo, A. y Areiza, A. (2013). Análisis del mercado de leche y derivados lácteos en Colombia (2008-2012). Recuperado de

http://www.sic.gov.co/recursos_user/d ocumentos/promocion_competencia/E $\underline{\text { studios_Economicos/Estudios_Econo }}$ $\underline{\text { micos/Estudio_Sectorial_Leche1.pdf }}$

Jaramillo, C. y Caicedo, E. (1996). Caracterización del ciclo ganadero. Recuperado de https://www.repository.fedesarrollo.or g.co/handle/11445/1386

Knight, F. (1947). Riesgo, incertidumbre y beneficio. Madrid, España: Aguilar Editor.

Legrand, C. (1988). Colonización y protesta campesina en Colombia, 1850 - 1950. Bogotá, Colombia: Universidad Nacional.

Lerner, A., Zuluaga, A., Chará, J., Etter, A. y Searchinger, T. (2017). Sustainable Cattle Ranching in Practice: Moving from Theory to Planning in Colombia's Livestock Sector, Enviromental Management, 60, 176-184. Recuperado de https://link-springercom.ezproxy.unal.edu.co/content/pdf/ 10.1007\%2Fs00267-017-0902-8.pdf

Llorente, L. (1986). La ganadería bovina en Colombia. En A. Machado (Ed.), Problemas agrarios colombianos (pp. 331 - 368). Bogotá, Colombia: Siglo XXI.

Llorente, L. (1994). Estrategias de desarrollo 
ganadero. Revista Coyuntura

Colombiana, 11, 111-182.

Londoño (2013). Estrategia Para una Empresa del Sector Ganadero en Colombia: Implementación del Sistema de Gestión "The Execution Premium" (135). Recuperado de https://repository.eafit.edu.co/handle/1 $\underline{0784 / 1324}$

López, A. (1927). Problemas colombianos. Paris, Francia: Paris- América.

Luhmann, N. (1995). Poder. Barcelona, España: Anthropos.

Luhmann, N. (2006). Sociología del riesgo. Ciudad de México, México: Universidad Iberoamericana.

Meisel, R. A (2017). El auge de las exportaciones de ganado del Caribe colombiano a Cuba, 1899-1906. En R. Román (Coordinador). Los movimientos de población y sus implicaciones en la economía. Ponencia llevada a cabo en el IV Congreso Internacional de la Asociación de Historia Económica del Caribe, San Andrés, Colombia.

Mejía, R. (2006). Administración del riesgo. Un enfoque empresarial. Medellín, Colombia: EAFIT.

Mejía, R. (2011). El riesgo y la historia empresarial antioqueña. Tres casos de estudio. Carlos E. Restrepo, José María Pepe Sierra, Ricardo Olano. Medellín, Colombia: Fondo Editorial EAFIT.

Mendoza, W. y Pérez, Y. (2016). Estudio del comportamiento de la producción de carne bovina en algunos países de América Latina mediante el uso de modelos de datos panel para el periodo de 1995-2014 (tesis de posgrado). Fundación Universitaria Los Libertadores, Bogotá.

Mintzberg, H. (1993). El juego del poder y los jugadores. En Ch. Ramió y X. Ballart (Ed.), Lecturas de Teoría de la organización (pp. 185 - 189). Madrid, España: Ministerio para las Administraciones Públicas.

Moré, G. (2003). Rancho Grande La historia de Coveñas. Recuperado de https://www.scribd.com/document/140 92881/2-Contenido-La-Historia-deCovenas

Morgan, G. (1991). Imágenes de la organización. Ciudad de México, México: Alfaomega.

Negrette, R. (2009). Una biografía parcial de Manuel Burgos y sus actividades empresariales en la Hacienda Berástegui. Cali, Colombia: 216 
RIESGO Y PODER EN LAS ORGANIZACIONES GANADERAS EN COLOMBIA. ENFOQUE DESDE LA HISTORIOGRAFÍA ECONÓMICA, SOCIAL Y EMPRESARIAL

Universidad Santiago de Cali.

Ocampo, G. (2007). La instauración de la ganadería en el valle del Sinú: la hacienda Marta Magdalena, 1881 1956. Medellín, Colombia: Universidad de Antioquia.

Ocampo, G. (2014). Poderes regionales, clientelismo y Estado. Etnografías del poder y la política en Córdoba, Colombia. Bogotá, Colombia: Odecofi, Cinep.

Peffer, J. (1993). Comprensión del papel que juega el poder en la toma de decisiones. En Ch. Ramió, y X. Ballart (Ed.), Lecturas de Teoría de la organización (pp.61 - 98). Madrid, España: Ministerio para las Administraciones Públicas.

Pérez, L. (2015). El cebuismo y la transformación agropecuaria del nororiente de Colombia durante el siglo XX. Ensayo de Economía, 46, 157-177. Recuperado de https://revistas.unal.edu.co/index.php/e de/article/download/53633/53079

Pertúz, A. (2008). Historia Empresarial de Sincelejo, Años 1936 - 1950. Revista Búsqueda, 9, 44-64

Posada, E. (1994). Historia económica del
Caribe colombiano Progreso y estancamiento 1850-1950. Bogotá, Colombia: Uninorte, ECOE, CERES.

Posada, E. (1988). La ganadería en la costa Atlántica colombiana, 1870-1950, Coyuntura económica, 18 (3), 143-175.

Posada, E. (2006). El Caribe colombiano. Una historia regional (1870-1950). Bogotá, Colombia: Banco de la República, Áncora Editores.

Reyes, A. (1978). Latifundio y poder político. La hacienda ganadera en Sucre. Bogotá, Colombia: Cinep.

Rivas, L. y Holmann, F. (2002). Sistema de doble propósito y su viabilidad en el contexto de los pequeños y medianos productores en América tropical. Curso de actualización en el manejo de ganado bovino de doble propósito. Recuperado de http://ciatlibrary.ciat.cgiar.org/Articulos_Ciat/tro pileche/sist_doble_prop_viab.pdf

Ripoll, M. (1997). El Central Colombia. Inicios de industrialización en el Caribe colombiano. Boletín Cultural del Banco de la República, 34(45), 59 - 92.

Ripoll, M. (1999). La actividad empresarial de Diego Martínez Camargo, 1890 - 1937 (2).

Recuperado de 
http://www.banrep.gov.co/es/actividadempresarial-diego-martiinez-camargo

Solano, S. (2008). Notas para un debate sobre el significado de la ganadería en la historia de la región Caribe colombiana. Cartagena, Colombia: Gente Nueva.

Solano, S. y Flórez, R. (2007). Resguardos indígenas, ganadería y conflictos sociales en el Bolívar Grande, 1850 1875. Historia crítica, 34, 92-117. Recuperado de http://www.scielo.org.co/pdf/rhc/n34/n $\underline{34 \mathrm{a} 05 . p d f}$

Solano, S., Flórez, R. y Malkun, W. (2010). Ganaderos y comerciantes: el manejo del poder político en el Estado Soberano de Bolívar (Colombia), 1857 - 1886. Historia y Sociedad, 18, 15-42. Recuperado de https://revistas.unal.edu.co/index.php/h isysoc/article/view/23582/24272

Staffe, A. (1961). Recomendaciones para la solución de algunos problemas de la ganadería en el departamento de Córdoba. Bogotá, Colombia: Departamento de investigaciones económicas de la Caja de Crédito Agrario.

Támara, R. (1961). Páginas sincelejanas.
Barranquilla, Colombia: Editorial Costa Libre.

Vargas, A. (1987). La ganadería en Colombia. Bogotá, Colombia: Banco de la República.

Viloria, J. (2003). La ganadería bovina en las llanuras del Caribe colombiano (40). Recuperado de http://www.banrep.gov.co/es/contenido s/publicacion/ganader-bovina-las$\underline{\text { llanuras-del-caribe-colombiano }}$

Viloria, J. (2005). La ganadería bovina en las llanuras del Caribe colombiano. En J. Gerson (Ed.), Microeconomía de la ganadería en Colombia (74 - 137). Cartagena, Colombia: Banco de la República.

Weber, M. (1994). Economía y Sociedad. Esbozo de sociología comprensiva. Bogotá, Colombia: Fondo de Cultura Económica.

Wright, C. (1987). La élite del poder. Ciudad de México, México. Fondo de Cultura Económica.

Zapata, B. (2006). Empresas comerciales del municipio de Valledupar (1950-1980). Valledupar, Colombia: Gobernación de Cesar. Observatorio del Caribe Colombiano. 